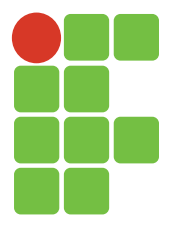

\title{
Constatação do "efeito sombra" e economia de recursos hídricos e de energia na irrigação do cafeeiro por meio de um pivô central convencional
}

Nara Cristina de Lima Silva ${ }^{1}$

Washington Luiz Assunção

\section{Resumo}

O pivô central é um sistema de irrigação que possibilita a aplicação de água em toda a área plantada. A observação do funcionamento de um pivô central convencional em campo, ao irrigar uma lavoura de cafeeiros adultos, possibilitou identificar um acúmulo de água nas extremidades dos dosséis das plantas em detrimento da região central das entrelinhas. Este trabalho teve como objetivo comprovar a influência do cafeeiro na interceptação da lâmina de irrigação aplicada por meio de um pivô central convencional, o que foi denominado pelos autores de "efeito sombra". Além disso, o trabalho buscou constatar a possibilidade de economia de recursos hídricos e de energia em função do "efeito sombra". O experimento foi realizado em uma área de 115,33ha plantada com duas cultivares do cafeeiro arábica (Cofeea arabica) onde foi coletada água aspergida pelo pivô central sob o dossel das plantas e nas entrelinhas. Os dados foram analisados estatisticamente por meio de análise descritiva e análise de variância, utilizando-se o software Action ${ }^{\circledR}$. Os resultados mostraram que as lâminas médias coletadas sob os dosséis foram maiores do que as lâminas médias coletadas nas entrelinhas para ambas as cultivares, e a lâmina interceptada pelo cafeeiro foi, em média, 30,4\% maior que a lâmina real aplicada pelo equipamento, comprovando-se o "efeito sombra" e, portanto, a possibilidade de economia de recursos hídricos e de energia.

Palavras-chave: Irrigação. Manejo sustentável. Economia. Cafeicultura.

\section{Introdução}

A expansão da cafeicultura em direção a novas fronteiras, a evolução dos sistemas de irrigação acompanhada de custos mais acessíveis dos equipamentos e a preocupação do cafeicultor com uma produção eficiente, que gere produtos de qualidade, são os principais fatores que tornam a irrigação do cafeeiro um tema de destaque nos últimos anos (SANTINATO et al., 2008). Basicamente, os sistemas de irrigação destinados a suprir as necessidades hídricas do cafeeiro podem ser divididos em dois grandes grupos: sistemas de irrigação em áreas totais e sistemas de irrigação em áreas localizadas; esses últimos irrigam parte da área do solo onde a cultura está implantada (FERNANDES et al., 2012). Na região do Triângulo Mineiro e Alto Paranaíba - estado de Minas Gerais - e no Oeste do estado da Bahia, há amplo emprego do pivô central em lavouras cafeeiras, onde são utilizados os denominados sprays convencionais para aplicação de água em toda a área plantada, sendo viável sua instalação em áreas superiores a 50ha (MANTOVANI, 2000). De acordo com levantamentos re-

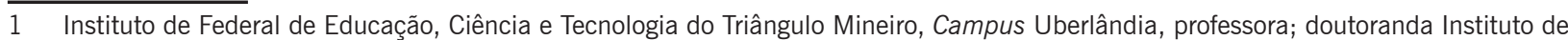
Geografia, Universidade Federal de Uberlândia. Uberlândia, Minas Gerais, Brasil. naracls@gmail.com (34) 3233-8800. Fazenda Sobradinho, s/n, Uberlândia, Minas Gerais, Caixa Postal 1020, CEP 38.400-970.

2 Universidade Federal de Uberlândia, professor Instituto de Geografia. Uberlândia, Minas Gerais, Brasil. assuncao@ufu.br (34) 32916321. Avenida João Naves de Ávila, 2121, Santa Mônica, Uberlândia, Minas Gerais, CEP 38408-100. 
alizados por Christofidis (2006), esse equipamento é empregado em cerca de 20,7\% de toda a área irrigada no Brasil. Observações acerca do funcionamento do pivô central em campo, ao irrigar uma lavoura de café em idade adulta, possibilitaram identificar um acúmulo de água nas extremidades dos dosséis do cafeeiro em detrimento da região central das entrelinhas. Esse fato seria justificado pela interceptação da água advinda dos aspersores pelas plantas, o que foi denominado "efeito sombra".

O sistema radicular do cafeeiro é do tipo pivotante, com raízes finas superficiais, que se localizam, em sua maioria (70 a $80 \%$ ), até 30 a $40 \mathrm{~cm}$ de profundidade do solo e até a projeção da copa (MATIELLO et al., 2010). A ocorrência do "efeito sombra", sob o ponto de vista técnico, seria positiva, já que haveria intercepção de maior parte da água aspergida no local de maior concentração de raízes. Em tese, esse acúmulo de água na região limitada pelo dossel do cafeeiro sugere que o pivô central convencional se comporte como um sistema "semilocalizado", pelo fato de grande parte da água precipitada ser interceptada e escorrer pelos ramos plagiotrópicos e ortotrópicos da planta. O "efeito sombra" já teria sido observado por Assunção (2002) ao pesquisar a cafeicultura irrigada no município de Araguari. No entanto, nenhum experimento foi realizado para comprovação desse fenômeno, o que torna esta pesquisa inédita. Diante do que foi exposto, o objetivo deste trabalho foi comprovar experimentalmente o "efeito sombra" quando se emprega o pivô central do tipo convencional na irrigação do cafeeiro e constatar a possibilidade de economia de recursos hídricos e de energia quando se leva em conta esse fenômeno.

\section{Materiais e métodos}

O experimento foi conduzido durante os meses de agosto e setembro de 2013, em uma área de 115,33ha, plantada com duas cultivares de café arábica (Coffea arabica) e irrigada por meio de um pivô central convencional. Essa área está localizada na bacia hidrográfica do Córrego Lageado, pertencente à Fazenda Quilombo, no município de Araguari (MG), cujas coordenadas geográficas são: 1843' de Latitude Sul e 4800' de Longitude a Oeste de Greenwich. A altitude é de 960m, medidos com GPS de navegação. O solo nessa região é classificado como Latossolo Vermelho Amarelo com textura variando de média a argilosa. O clima é do tipo Aw segundo Köppen, isto é, tropical semiúmido, com duas estações bem definidas ao longo do ano: verão chuvoso (outubro a março), que responde por, aproximadamente, $85 \%$ do total anual das chuvas, e inverno seco nos outros seis meses restantes (abril a setembro). A temperatura média anual é de $21,9^{\circ} \mathrm{C}$, estimada conforme Assunção (2002), e a precipitação média anual é de 1.520mm (OLIVEIRA; ASSUNÇÃO, 2013).

As duas cultivares de café arábica (Coffea arabica) foram implantadas nessa área no ano de 1998. A metade da área total é ocupada pela variedade Catuaí e a outra metade da área é ocupada pela variedade Mundo Novo. 0 espaçamento é de 4,00m entre linhas e 0,7m entre plantas em toda a lavoura, sendo a altura média dos pés de café, na ocasião da realização deste trabalho, de 2,40m para a variedade Mundo Novo, a qual foi decotada no mês de setembro de 2012, e altura média de 3,20m para a variedade Catuaí. O diâmetro do dossel variou de 1,90 a 2,00m para as duas cultivares.

O pivô central avaliado possui as seguintes características principais: marca VALLEY ${ }^{\circledR}$, modelo 4871-8000 - VSL/11-1502, com 11 torres mais o vão em balanço, sendo 8 lance longo de 6.5/8" (54m cada um), 3 lance médio de 6.5/8" (48m cada um) e balanço de $25 \mathrm{~m}$ com um spray final, totalizando 608,58m de tubulação da linha lateral, considerando o comprimento das junções. A área circular irrigada é de 116,93 ha e o raio total irrigado é de 610,08m. A linha lateral está suspensa pela torre a uma altura de $5,40 \mathrm{~m}$ do solo, sendo os aspersores $(30 \mathrm{~cm})$ posicionados sobre ela. Para deslocamento, possui motorredutores de 1,2CV (alta velocidade). O período (relê a 100\%) é de 13,88 h e a lâmina aplicada, por volta, é de $4,05 \mathrm{~mm}$, considerando um giro de $360^{\circ}$. A vazão por 
área é de $2,92 \mathrm{~m}^{3} \mathrm{~h}^{-1} \mathrm{ha}^{-1}$, sendo a vazão total de $341,04 \mathrm{~m}^{3} \mathrm{~h}^{-1}$. A pressão no final da tubulação é de 13 mca e a pressão no ponto do pivot é de 45,69mca. A adutora é de aço zincado de $250 \mathrm{~mm}$ de diâmetro e $1.000 \mathrm{~m}$ de comprimento. 0 desnível entre a motobomba e o centro do pivô é de $50 \mathrm{mca}$ e o desnível entre o centro do pivô e o ponto mais alto da área é de Omca. O motor elétrico é de 250CV, a rotação de $1750 \mathrm{rpm}$ e o consumo de energia da bomba centrífuga é de 168,59kwh-1.

Para determinação da uniformidade de aplicação de água pelo pivô central em estudo, determinou-se o Coeficiente de Uniformidade de Christiansen (CUC), proposto por Christiansen (1942) e modificado por Heermann e Hein (1968). Conforme determinado pela NBR 14.244 (1998), as linhas de coletores foram dispostas desde o centro do pivô até o extremo da área irrigada ao longo de dois carreadores principais e perpendiculares entre si, sendo a distância entre coletores de $5 \mathrm{~m}$.

As condições de tempo locais, como temperatura do ar, umidade relativa e velocidade do vento, foram determinadas por meio de um Termo-Higro-Anemômetro Luxímetro digital e portátil da marca Politerm ${ }^{\circledR}$, Modelo LM 8000.

Para averiguar a influência do cafeeiro na distribuição da água durante a irrigação, coletaram-se lâminas nos dois locais de interesse: entre linhas e sob os dosséis das plantas. Utilizaram-se, para coleta das lâminas, estruturas construídas com ripas de madeira cobertas por uma lona de plástico muito resistente. As estruturas menores ( $1 \mathrm{~m} \times 1 \mathrm{~m}$ ) eram amparadas por uma viga de metal e outras, de maior tamanho $(2 \mathrm{~m} \times 1 \mathrm{~m})$, não foram amparadas por viga de metal, mas por outra ripa de madeira disposta em sentido transversal, a fim de suportar melhor a quantidade de água e também para facilitar o seu transporte durante o experimento.

As dimensões das estruturas foram definidas em função do diâmetro do dossel e do espaçamento entre linhas. Essas estruturas foram dispostas na lavoura de maneira que pudessem representar toda a área coberta pelos cafeeiros, tanto da cultivar Mundo Novo quanto da cultivar Catuaí. Assim, para cada cultivar, ou seja, para cada metade da área irrigada pelo pivô central, selecionaram-se dois locais de coleta entre torres, exceto entre a torre do ponto pivô e a primeira torre móvel, totalizando 10 pontos de amostragem, com 1 repetição em cada ponto. Em cada local de coleta, foram dispostos três coletores, sendo dois deles $(1 \mathrm{~m} \times 1 \mathrm{~m})$ posicionados sob os dosséis do cafeeiro, em lados opostos, na mesma entrelinha, com o objetivo de coletar o volume de água correspondente à interceptação de todo o dossel da planta. 0 terceiro coletor $(2 \mathrm{~m} \times 1 \mathrm{~m})$ foi posicionado no meio da entrelinha (Figura 1 ).
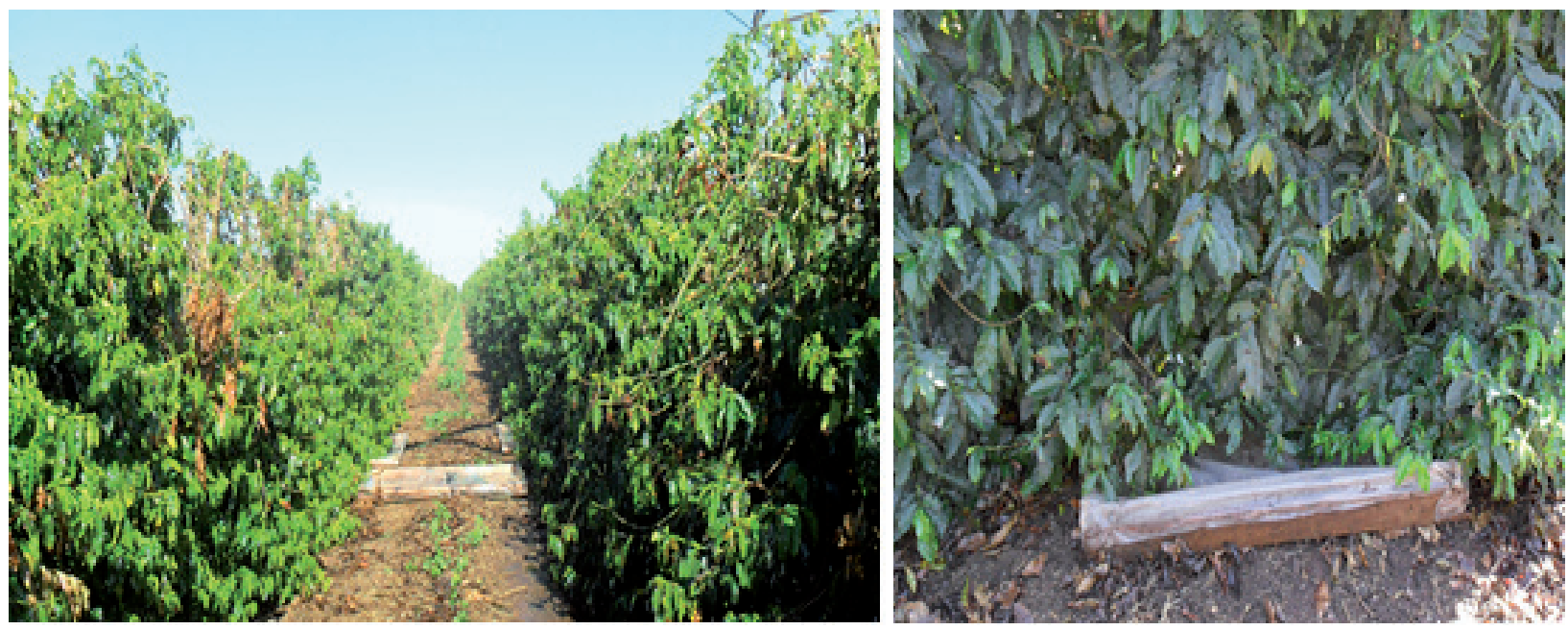

Figura 1. Estruturas coletoras em campo, após passagem do pivô central (esquerda) e detalhe de uma das estruturas posicionada sob o dossel (direita).

Fonte: Elaboração dos autores. 
As coletas e as quantificações das lâminas foram conduzidas na medida em que o pivô central passava pelos pontos de amostragem e as estruturas coletoras eram reposicionadas na direção do movimento da linha lateral até finalização da coleta no décimo ponto, considerando, primeiramente, a área ocupada pelo cafeeiro da cultivar Catuaí. 0 mesmo procedimento foi adotado para realização do experimento na outra metade da área, ou seja, aquela ocupada pelo cafeeiro da cultivar Mundo Novo. Na Figura 2 está esquematizado o experimento em campo.

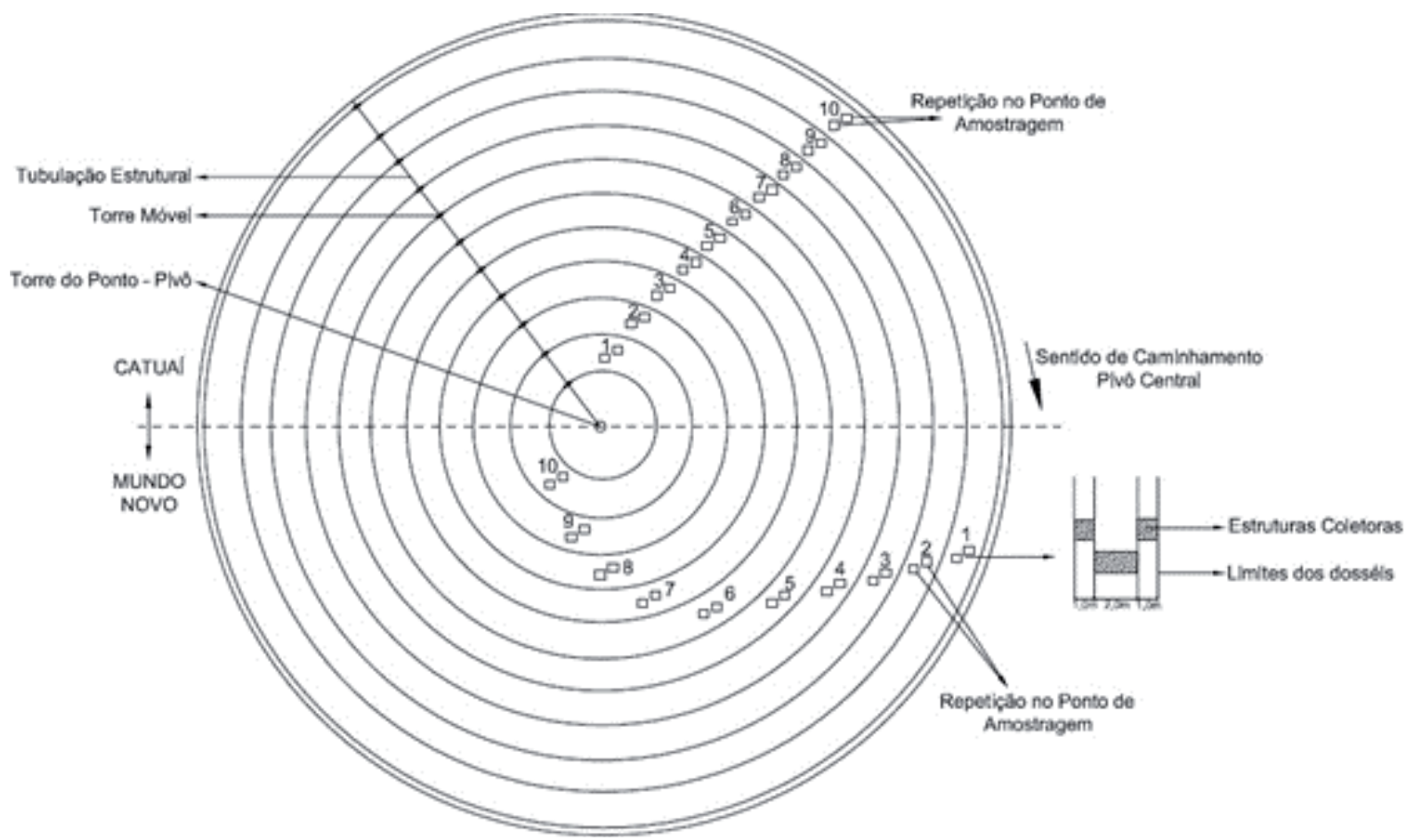

Figura 2. Desenho esquemático do experimento executado em campo, considerando as áreas ocupadas pelas cultivares Catuaí e Mundo Novo.

Fonte: Elaboração dos autores.

Para a quantificação da água aspergida em cada coletor, após a passagem do pivô central, utilizaram-se baldes de $5.000 \mathrm{~mL}$ e provetas de $1.000 \mathrm{~mL}$. A razão entre os volumes de água recolhidos e a área de cada coletor forneceu a lâmina de água aspergida sob os dosséis e nas entrelinhas, em mm. A lâmina média recolhida sob os dosséis correspondeu à soma das lâminas recolhidas sob os dosséis em lados opostos de uma mesma entrelinha. Igualmente, conforme realizado para determinação do coeficiente de uniformidade (CUC) e utilizando o mesmo equipamento de medição, foram determinadas as condições de tempo locais realizando-se leituras de temperatura do ar, velocidade do vento e umidade relativa no início e durante os testes (Tabela 1).

Tabela 1. Valores médios de temperatura do ar, umidade relativa e velocidade do vento durante o ensaio para determinação do CUC e durante o ensaio para comprovação do "efeito sombra", considerando as duas cultivares irrigadas (Catuaí e Mundo Novo).

\begin{tabular}{cccc}
\hline Ensaios & Temperatura do ar $\left({ }^{\circ} \mathrm{C}\right)$ & Umidade Relativa (\%) & $\begin{array}{c}\text { Velocidade do Vento } \\
\left(\mathrm{m} \mathrm{s}^{-1}\right)\end{array}$ \\
\hline CUC & 23 & 66 & 2,10 \\
"efeito sombra"- Catuaí & 30 & 43 & 1,67 \\
"efeito sombra"- Mundo Novo & 28 & 55 & 2,53 \\
\hline
\end{tabular}

Fonte: Elaboração dos autores. 
Os dados foram inicialmente analisados por meio da estatística descritiva, tendo como base as seguintes medidas: Média Aritmética, Mediana, Desvio-Padrão, Variância, Máximo, Mínimo e Coeficiente de Variação. $O$ teste de Anderson - Darling, a 5\% de probabilidade, foi utilizado para verificar se os dados apresentavam Distribuição Normal. Constatada a Normalidade, aplicou-se o Teste F para verificação da homogeneidade das variâncias e, em seguida, aplicou-se o Teste T para comparação da lâmina recolhida abaixo do dossel com a lâmina recolhida na entrelinha para ambas as cultivares. Ainda por meio do Teste T, comparou-se a lâmina média real aplicada pelo pivô central e a lâmina que foi interceptada pelo cafeeiro. Todos os procedimentos referentes às análises estatísticas foram efetuados com auxílio do software Action $^{\circledR}$ (ESTATCAMP CONSULTORIA ESTATÍSTICA, 2013), desenvolvido sob a plataforma R (R DEVELOPMENT CORE TEAM, 2013).

\section{Resultados e discussão}

O valor médio do CUC foi de 87,89\%, classificando a uniformidade de aplicação do pivô central como Boa (85 a 89\%), conforme a NBR 14244 (1998). Em relação à velocidade do vento, durante este ensaio, verificou-se que os valores médios não ultrapassaram o permitido na norma, a qual estabelece que velocidades superiores a 3,0 $\mathrm{m} \mathrm{s}^{-1}$ invalidam os testes. Quanto aos valores de temperatura e umidade relativa, registraram-se os valores esperados, considerando a região geográfica e a época do ano em que os ensaios foram realizados (Tabela 1 ).

$\mathrm{Na}$ Tabela 2, encontra-se a estatística descritiva dos dados correspondentes ao experimento realizado em campo onde foi coletada a lâmina de irrigação em cada local de interesse (sob o dossel e na entrelinha) nas áreas correspondentes ao plantio das cultivares Catuaí e Mundo Novo.

Tabela 2. Estatística descritiva das lâminas coletadas abaixo do dossel e na entrelinha considerando as duas cultivares irrigadas (Catuaí e Mundo Novo).

\begin{tabular}{ccccc}
\hline & \multicolumn{4}{c}{ Lâmina Coletada (mm) } \\
\cline { 2 - 5 } Estatística Descritiva & Dossel Catuaí & $\begin{array}{c}\text { Entrelinha } \\
\text { Catuaí }\end{array}$ & $\begin{array}{c}\text { Dossel } \\
\text { Mundo Novo }\end{array}$ & $\begin{array}{c}\text { Entrelinha } \\
\text { Mundo Novo }\end{array}$ \\
\hline Média & 36,84 & 21,09 & 38,83 & 19,33 \\
Mediana & 35,70 & 21,41 & 39,46 & 19,76 \\
Variância & 51,73 & 11,17 & 77,66 & 27,55 \\
Desvio Padrão & 7,19 & 3,34 & 8,81 & 5,25 \\
Máximo & 51,36 & 26,00 & 59,36 & 31,68 \\
Mínimo & 22,68 & 15,63 & 24,08 & 7,42 \\
CV1 (\%) & 19,52 & 15,85 & 22,70 & 27,16 \\
\hline
\end{tabular}

${ }^{1} \mathrm{CV}$ : coeficiente de variação.

Fonte: Elaboração dos autores.

As medidas de tendência central (Média e Mediana) tiveram pouca variação, se se considerar cada um dos pontos de coleta da lâmina de irrigação (Dossel-Catuaí, Entrelinha-Catuaí, Dossel-Mundo Novo, Entrelinha-Mundo Novo), o que indica uma distribuição cujos dados apresentaram reduzido afastamento de um valor central, confirmado pelo teste de Normalidade de Anderson - Darling a 5\% (Tabelas 2 e 3). 
Tabela 3. Teste de Normalidade (Anderson-Darling) para o conjunto de dados coletados

\begin{tabular}{ccc}
\hline Local de coleta da lâmina & Estatística Anderson-Darling & P-Valor ${ }^{1}$ \\
\hline Dossel-Catuaí & 0,3426 & 0,4547 \\
Entrelinha-Catuaí & 0,3498 & 0,4371 \\
Dossel-Mundo Novo & 0,2137 & 0,8271 \\
Entrelinha-Mundo Novo & 0,3784 & 0,3728 \\
\hline
\end{tabular}

${ }^{1} 0 \leq 0,05$ de probabilidade.

Fonte: Elaboração dos autores.

As lâminas médias coletadas sob os dosséis foram maiores do que as lâminas médias coletadas nas entrelinhas para ambas as cultivares (Catuaí e Mundo Novo), indicando influência do cafeeiro na interceptação da lâmina advinda dos aspersores do pivô central. Os valores de Máximo e de Mínimo também indicam essa tendência. No entanto, maiores valores do Desvio Padrão, considerando os valores médios, foram determinados para as lâminas coletadas abaixo dos dosséis, o que pode estar relacionado ao fato de que o cafeeiro possui densidade de folhas heterogêneas na lavoura, influenciando, portanto, na lâmina de água coletada nesse local (Tabela 2).

Analisando o Coeficiente de Variação (CV), observou-se que, segundo a classificação proposta por Warrick e Nielsen (1980), considerando como valores baixos o CV $<12 \%$, médios para $12 \%<$ CV $<60 \%$ e altos para CV $>60 \%$, todas as lâminas recolhidas encontraram-se no intervalo de 12 a $60 \%$, sendo, portanto, consideradas de média variação.

Constatada a Normalidade dos dados ( $\mathrm{P}$ - valor maior que 5\%, Tabela 3), aplicou-se o Teste $\mathrm{F}$ para verificação da homogeneidade das variâncias, por meio do qual constatou-se que, ao comparar a lâmina de irrigação recolhida sob o dossel com a lâmina de irrigação recolhida no meio da entrelinha, para ambas as cultivares, as variâncias foram heterogêneas $(P$ - valor de 0,0015 e 0,0029, respectivamente, para as cultivares Catuaí e Mundo Novo, Tabela 4).

Tabela 4. Teste F para homogeneidade de variâncias e Teste T para comparação da lâmina de água recolhida, tanto sob o dossel quanto na entrelinha, para ambas as cultivares irrigadas (Catuaí e Mundo Novo)

\begin{tabular}{cccccc}
\hline \multirow{2}{*}{ Variedade } & \multirow{2}{*}{ Local } & \multicolumn{2}{c}{ TESTE F } & \multicolumn{2}{c}{ TESTE T } \\
\cline { 3 - 6 } & dossel & Variância & P-valor ${ }^{1}$ & Média & P-valor $^{1}$ \\
\hline \multirow{2}{*}{ Catuaí } & 51,73 & \multirow{2}{*}{0,001598} & 36,84 & \multirow{2}{*}{0,001} \\
& entrelinha & 11,17 & & 21,09 & $<$ \\
\hline \multirow{2}{*}{ Mundo Novo } & dossel & 77,66 & \multirow{2}{*}{0,0029} & 38,83 & $<0,001$ \\
& entrelinha & 27,55 & & 19,33 & \multirow{2}{*}{} \\
\hline
\end{tabular}

${ }^{1} \mathrm{p}$ - valor $\leq 0,05$ : significativo.

Fonte: Elaboração dos autores.

Essa análise, complementada com o resultado do Teste T (Tabela 4), confirma que houve diferença estatística ao se comparar a lâmina de água recolhida sob o dossel com a lâmina de água recoIhida na entrelinha, para ambas as cultivares. Observa-se que a lâmina média coletada sob o dossel foi $42,76 \%$ e 50,22\% maior que a lâmina média coletada na entrelinha, respectivamente, para as cultivares Catuaí e Mundo Novo, confirmando, portanto, o "efeito sombra" provocado pelo cafeeiro.

Ao comparar o maior ou menor "efeito sombra" entre cultivares, em função da altura das plantas, constatou-se que não houve diferença estatística entre elas, ou seja, a diferença de, aproximadamente, $80 \mathrm{~cm}$ na altura das plantas não determinou maior ou menor interferência na distribuição da lâmina de água pelo pivô central (Tabela 5). 
Tabela 5. Teste F para homogeneidade de variâncias e Teste T para comparação do "efeito sombra" entre as cultivares irrigadas (Catuaí e Mundo Novo)

\begin{tabular}{ccccc}
\hline \multirow{2}{*}{ Local/Variedade } & \multicolumn{2}{c}{ TESTE F } & \multicolumn{2}{c}{ TESTE T } \\
\cline { 2 - 5 } & Variância & P-valor $^{1}$ & Média & P-valor $^{1}$ \\
\hline dossel-Catuaí & 51,73 & \multirow{2}{*}{0,38385} & 36,84 & \multirow{2}{*}{0,4398} \\
dossel-Mundo Novo & 77,66 & & 38,83 & \multirow{2}{*}{0,2148} \\
\hline entrelinha-Catuaí & 11,17 & \multirow{2}{*}{0,05596} & 21,09 & \\
entrelinha-Mundo Novo & 27,55 & & 19,33 & \\
\hline
\end{tabular}

${ }_{1}^{1}$ p- valor $\leq 0,05$ : significativo.

Fonte: Elaboração dos autores.

Finalmente, comparou-se a lâmina recolhida sob o dossel-Catuaí $(36,84 \mathrm{~mm})$ e sob o dossel-Mundo Novo (38,83 mm) com a lâmina média real (LMR) aplicada pelo pivô central (29,02 mm), por meio do Teste T (Tabela 6).

Tabela 6. Teste T para comparação da lâmina recolhida abaixo dos dosséis das plantas (Cultivares Catuaí e Mundo Novo) com a LMR aplicada pelo pivô central

\begin{tabular}{ccc}
\hline \multirow{2}{*}{ Lâmina } & \multicolumn{2}{c}{ TESTE T } \\
\cline { 2 - 3 } & Média & P-valor $^{1}$ \\
\hline dossel-Catuaí & 36,84 & $<0,001$ \\
LMR & 29,02 & $<0,001$ \\
\hline dossel- Mundo Novo & 21,09 & $<$ \\
LMR & 29,02 & \multirow{2}{*}{} \\
\hline
\end{tabular}

${ }^{1} p$ - valor $\leq 0,05$ : significativo.

Fonte: Elaboração dos autores.

Nesse caso, a LMR aplicada foi determinada por meio das médias das lâminas recolhidas sob o dossel e nas entrelinhas, considerando o experimento realizado na área ocupada pelas duas cultivares. De acordo com os valores apresentados, observa-se que a lâmina de água recolhida sob os dosséis é estatisticamente distinta da LMR, comprovando-se mais uma vez que há interferência do cafeeiro na interceptação da água advinda dos aspersores.

Comparando-se a LMR com a lâmina média recolhida sob os dosséis da variedade Catuaí, por exemplo, confirma-se que houve a aplicação de 26,95\% a mais de água, ou seja, 7,82 mm, o que equivale a um excedente médio de $4.509 \mathrm{~m}^{3}$ de água, por meia volta do pivô central, nessa lavoura. Refazendo-se os mesmos cálculos, considerando, agora, o cafeeiro da variedade Mundo Novo, a economia de água seria em média de $5.656 \mathrm{~m}^{3}$ novamente por meia volta do pivô central. Nesse caso, a aplicação excedente de 9,81 mm equivale a 33,80\% a mais de água.

A observação do "efeito sombra", previamente realizada por Assunção (2002) e comprovada por meio deste experimento, mostrou então que houve, em média, um excesso de 30,4\% de água sendo aplicada, por volta do pivô central, nessa lavoura. Ressalta-se que a averiguação da quantidade de lâmina interceptada pela planta deve ser realizada para cada situação, ou seja, considerando a altura mínima para ocorrer a interceptação da água pela cultura, o espaçamento entrelinhas, enfolhamento e diâmetro dos dosséis, condições de clima e tempo locais e outros.

Tomando como referência novamente a presente área irrigada e o funcionamento técnico do equipamento, se a $\operatorname{LMR}(29,02 \mathrm{~mm})$ puder ser reduzida em 30,4\% (20,20 mm), a relê atual $(12,26 \%)$ passaria a ser de $17,62 \%$. Isso significa que o pivô gastaria $78,77 \mathrm{~h}$ (3d e $7 \mathrm{~h}$ ), em vez de $113,12 \mathrm{~h}$ (4d e 17h), para completar uma volta na área. A diferença de $1 \mathrm{~d}$ e $10 \mathrm{~h}$ a menos na 
irrigação da lavoura significa a economia de 8,82mm de água, ou seja, $10.172 \mathrm{~m}^{3}$, por volta, do equipamento na área. Se a bomba centrífuga consumir, em média, 168,59kWh, a economia energética será de $\mathrm{R} \$ 501,81$, por volta do pivô central, considerando o custo médio de $\mathrm{R} \$ 0,086352$ por kWh (COMPANHIA ENERGÉTICA DE MINAS GERAIS-CEMIG, 2014).

Considerando que o pivô executa, nessa área, em média, 17 voltas por ano, de acordo com o manejo realizado, a economia seria de $172.924 \mathrm{~m}^{3}$ de água. Esse volume seria o suficiente para suprir as necessidades diárias de 2.369 pessoas, considerando o consumo médio de $200 \mathrm{Lhab}^{-1} \mathrm{dia}^{-1}$ (CHRISTOFIDIS, 2006), em uma cidade de porte médio no Brasil. Quanto aos gastos com energia, a economia seria de $\mathrm{R} \$ 8.501,85$. Há de se considerar, ainda, a energia gasta para manter o giro do pivô, o que não foi contabilizado nesse cálculo.

Por fim, mas não menos importante, torna-se fundamental ressaltar que a utilização sustentável dos recursos hídricos é essencial para um manejo econômico do sistema de irrigação. A outorga e a cobrança pelo uso dos recursos hídricos, instrumentos de gestão consolidados pela Lei no 9.433, de 8 de janeiro de 1997, são uma realidade e já ocorrem em várias bacias hidrográficas.

Por meio da análise do uso da terra e de dados resultantes do balanço hídrico para a bacia do Córrego Lajeado, área na qual foi realizado este estudo, foram caracterizados os principais fatores de escassez hídrica, sendo verificado que, durante a estação seca, a necessidade por irrigação é muito grande, o que aumenta a demanda dos recursos hídricos, podendo fomentar, no futuro, um conflito pelo uso da água entre os usuários. A garantia de expansão da área irrigada nessa bacia está diretamente relacionada com a melhoria das condições de irrigação atuais e com a análise da capacidade máxima de suporte de exploração dos recursos disponíveis (OLIVEIRA; ASSUNÇÃO, 2013).

Outra questão importante a considerar é a eficiência do uso da água na agricultura irrigada. No Brasil, a agricultura irrigada tem uma eficiência média de apenas 60\%, o que implica riscos de danos ambientais tais como o de salinização dos solos e de dispersão de fertilizantes e defensivos agrícolas (COELHO et al., 2005).

Corroborando o que foi exposto, recentemente, foi sancionada a Lei $n^{\circ} 12.787$, de 11 de janeiro de 2013, cujo objetivo é a expansão das áreas irrigadas no país. Esse documento prevê o uso e o manejo sustentável dos solos e recursos hídricos destinados à irrigação, o que foi constituído como um dos princípios básicos dessa nova Lei, que estabelece a outorga como critério para projetos de irrigação.

\section{Conclusões}

Por meio deste experimento, comprovou-se que ocorre um acúmulo de água nos dosséis do cafeeiro em detrimento da região central das entrelinhas, quando a lavoura é irrigada por um pivô central convencional. Esse fenômeno foi denominado "efeito sombra", dada a influência da altura do cafeeiro na uniformidade da irrigação na lavoura.

A interferência do cafeeiro, ao interceptar a lâmina de irrigação aplicada pelo pivô central, causou, em média, a concentração de 30,4 \% dessa lâmina nos dosséis das plantas. Essa interceptação torna a irrigação em área total parecida com a irrigação em área localizada, favorecendo a formação de um bulbo de molhamento mais acentuado nos limites dos dosséis, auxiliando no maior desenvolvimento radicular da planta e, por conseguinte, na maior absorção de nutrientes e incrementos na produtividade.

Embora não tenha sido encontrada diferença estatística ao se compararem os resultados em áreas de cafeeiros com 2,40m e 3,20m de altura, a quantidade da água interceptada deve ser quantificada para cada situação, considerando a altura mínima da planta que tem influência na intercep- 
tação: o espaçamento entrelinhas, o enfolhamento e diâmetro dos dosséis, as condições de clima e tempo locais, em especial, as condições de velocidade do vento.

Com a comprovação do "efeito sombra", constatou-se a possibilidade de economia de recursos hídricos e de energia ao propor ajuste do relê cíclico (temporizador) do equipamento em campo.

\title{
"Shadow effect" finding and water and power resource savings on irrigating coffee crop by using a conventional center pivot
}

\begin{abstract}
A center pivot system can irrigate an entire field. By observing the operation of a conventional center pivot irrigating an adult coffee crop, it is possible to identify accumulation of water at the ends of plant canopies rather than the central region between the lines. We determined the influence of coffee plant interception on the irrigation depth from a conventional center pivot system. We refer to this as the "shadow effect." In addition, the study aimed to provide the economy of water resources and energy due to the "shadow effect". The experiment was conducted in an area of 115.33ha planted with two varieties of Arabica coffee (Cofeea arabica) which was collected by center pivot spraying water under the plant canopy and the lines. The resulting data were analyzed by descriptive analysis and variance analysis using the Action tool. The results showed that the irrigation depth intercepted by the coffee canopy was $30.4 \%$ greater than the actual depth from the irrigation system confirming the "shadow effect" and therefore the possibility of water resources and power saving.
\end{abstract}

Keywords: Irrigation. Sustainable Management. Saving. Coffee production.

\section{Referências}

ASSOCIAÇÃO BRASILEIRA DE NORMAS TÉCNICAS. NBR 14244: Equipamentos de irrigação mecanizada - Pivô central e lateral móvel providos de emissores fixos ou rotativos - Determinação da uniformaidade de distribuição de água. Rio de Janeiro, 1988. 11 p.

ASSUNÇÃO, W. L. Climatologia da cafeicultura irrigada no município de Araguari (MG). 2002. 266f. Tese (Doutorado em Geografia). Faculdade de Ciências e Tecnologias, Universidade Estadual Paulista, Presidente Prudente.

BRASIL. Lei no 9.433, de 8 de janeiro de 1997. Institui a Política Nacional de Recursos Hídricos, cria o Sistema Nacional de Gerenciamento de Recursos Hídricos, regulamenta o inciso XIX do art. 21 da Constituição Federal, e altera o art. $1^{\circ}$ da Lei no 8.001, de 13 de março de 1990, que modificou a Lei $n^{0}$ 7.990, de 28 de dezembro de 1989. Diário Oficial [da] República Federativa do Brasil, Brasília, DF, 8 jan. 1997. Disponível em: <http://www.planalto.gov.br/ccivil 03/leis/L9433.htm>. Acesso em: 20 jan. 2014.

BRASIL. Lei n. ${ }^{\circ} 12$ 787/2013, de 11 de janeiro de 2013. Dispõe sobre a Política Nacional de Irrigação; altera o art. 25 da Lei no 10.438, de 26 de abril de 2002; revoga as Leis nos 6.662 , de 25 de junho de 1979, 8.657, de 21 de maio de 1993, e os Decretos-Lei nos 2.032, de 9 de junho de 1983, e 2.369, de 11 de novembro de 1987; e dá outras providências. Diário Oficial [da] Repú- 
blica Federativa do Brasil, Brasília, DF, 8 jan. 1997. Disponível em: < http://www.planalto.gov.br/ ccivil_03/_Ato2011-2014/2013/Lei/L12787.htm>. Acesso em: 20 jan. 2014.

CHRISTIANSEN, J. E. Irrigation by sprinkling. Berkeley, California: Agricultural Station, 1942. 124p. (Bulletin, 670).

CHRISTOFIDIS, D. Água na produção de alimentos: o papel da academia e da indústria no alcance do desenvolvimento sustentável. Revista Ciências Exatas, Taubaté, v. 12, n. 1, p. 37- 46, jan./jun. 2006.

COELHO, E. F; COELHO FILHO, M. A.; OLIVEIRA, S. L. Agricultura irrigada: eficiência de irrigação e de uso de água. Bahia Agrícola, Salvador, v. 7, n. 1, p. 57-60, set. 2005. Disponível em:<http:// www4.seagri.ba.gov.br/pdf/socioeconomia4_v7n1.pdf>. Acesso em: 25 jan. 2015.

COMPANHIA ENERGÉTICA DE MINAS GERAIS - CEMIG. Atendimento. Valores de tarifas e serviços. Disponível em: < http://application.voxage.com.br/voswebchatserver/pages/init.jsp?time $=1394751772015>$. Acesso em: 12 mar. 2014.

ESTATCAMP CONSULTORIA ESTATÍSTICA. Portal action. São Carlos, 2013. Disponível em: < http:// www.portalaction.com.br>. Acesso em: 02 out. 2013.

FERNANDES, A. L. T.; PARTELLI, F.L.; BONOMO, R.; GOLYNSKI, A. A moderna cafeicultura dos cerrados brasileiros. Pesquisa Agropecuária Tropical, Goiânia, v. 42, n. 2, p. 231-240, abr./jun. 2012.

HEERMANN, D. F.; HEIN, P. R. Performance characteristics of self propelled center-pivot sprinkler irrigation system. Transactions of the ASAE, Saint Joseph, v. 11, n. 1, p. 11-15, 1968.

MANTOVANI, E. C. A irrigação do cafeeiro. ITEM: Irrigação e Tecnologia Moderna, Brasília, v. 3, n. 48, p. 45-49, jul./set. 2000.

MATIELlO, J. B.; SANTINATO, R.; GARCIA, A. W. R.; ALMEIDA, S. R. FERNANDES, D. R. Cultura de café no Brasil: manual de recomendações. Rio de Janeiro: MAPA/PROCAFÉ; Varginha: PROCAFÉ, 2010. 542 p.

OLIVEIRA, D. A.; ASSUNÇÃO, W. L. O uso da água e do solo da bacia hidrográfica do córrego Lajeado, Araguari - MG. Caminhos da Geografia, Uberlândia, v. 14, n. 46, p. 204-219, jun. 2013.

R DEVELOPMENT CORE TEAM. R: A language and environment for statistical computing. 2013. Vienna: R Foundation for Statistical Computing, 2013. Disponível em: <http://www.r-project.org/isbn 3- 900051-07-0>. Acesso em: out. 2013.

SANTINATO, R.; FERNANDES, A. L. T.; FERNANDES, D. R. Irrigação na cultura do café. 2. ed. Belo Horizonte: O Lutador, 2008. 476 p.

WARRICK, A. W.; NIELSEN, D. R. Spatial variability of soil physical properties in the field. In: HILLEL, D. Application of soil physics. New York: Academic Press, 1980.

\section{Histórico editorial}

Submetido em: 23/05/2014

Aceito em: 10/02/2015 